ESTUDIOS Y ENSAYOS 



\title{
El reformismo alarconiano en El dueño de las estrellas y La crueldad por el honor
}

\author{
Ysla CAMPBell \\ Universidad Autónoma de Ciudad Juárez \\ yslacampbell@live.com
}

\begin{abstract}
Resumen: Durante el reinado de Felipe III y su valido el duque de Lerma, la crisis económica y la vertiginosa caída de la aplicación de la ley con su contrario, la corrupción, el cohecho, la venta de cargos, desembocó en una serie de memoriales, arbitrios y libros en los que se sugerían remedios para salir de dicha situación. En este contexto histórico, Juan Ruiz de Alarcón escribe El dueño de las estrellas y La crueldad por el honor, dos tragedias en las que destaca el papel de la formulación de nuevas leyes. En el texto se analiza la relación entre las leyes propuestas en las obras y las de los pensadores reformistas del Siglo de Oro.
\end{abstract}

AвSTRACT: The economic crisis and the vertiginous fall in the application of the law with its opposite, corruption, bribery, the sale of posts in the reign of Philip III and his valid the Duke of Lerma, lead to a series of memorials, "arbitrios" and books which suggested remedies to get out of this situation. In this historical context, Juan Ruiz de Alarcón writes El dueño de las estrellas and La crueldad por el honor, two tragedies which manifest the role of the formulation of new laws. The text analyses the relationship between laws proposed in the plays and the reformist thinkers of the Golden age

Palabras Clave: legalidad, leyes, reforma, Alarcón, duque de Lerma, Olivares. KeYwords: legalidad, leyes, reforma, Alarcón, duque de Lerma, Olivares.

Es de todos conocido que durante el reinado de Felipe III y su privado, el duque de Lerma, la corrupción, el cohecho y la venta de cargos alcanzaron niveles inusitados. El desplome de la legalidad se sumó a la crisis económica que venía arrastrándose desde el reinado de Felipe II. En 1598, a su muerte, los ingresos de la Hacienda eran alrededor de diez millones de ducados, mientras la deuda externa era de unos sesenta y ocho millones (Domínguez Ortiz: 313). La situación, agudizada por la extrema liberalidad en las mercedes a costa de un tesoro real muy mermado, el afán desmedido de lucro y la despoblación significaron una abundante producción de textos de arbitristas, moralistas, políticos 
y economistas que proponían diversas reformas. ${ }^{1}$ En medio de dicha coyuntura, Alarcón plantea algunas propuestas legislativas en El dueño de las estrellas (1620-1623) y en La crueldad por el honor (1621-1622), cuyos nexos con los planteamientos reformistas pretendo analizar.

En El dueño los proyectos legales los hace el legendario legislador espartano Licurgo; en La crueldad, curiosamente, el gracioso Zaratán, quien dice ser inclinado al legislador ateniense Solón. Ambas obras coinciden en que las leyes propuestas son aceptadas por los gobernantes.

Basado en el oráculo de Apolo, el Rey de Creta solicita a Licurgo que gobierne con él para garantizar la paz del reino, y se conduzcan como una sola persona: "en mí ha de estar la corona, / pero mi poder en vos" (vv. 965-966). Entre las razones que aduce el legislador para no aceptar la propuesta, la más importante es que los astros le pronosticaron que mataría a un rey o moriría a sus manos. No obstante, ante los razonamientos del Rey accede a servirlo. Las primeras acciones del monarca son nombrarlo Gobernador general, delegarle toda su soberanía en los vasallos y otorgarle total autoridad con una sortija: "Éste es mi sello real; / por él han de obedeceros" (vv. 1294-1295). Esta simbiosis y la concesión del sello real recuerdan la cédula de 1612, en la cual Felipe III otorgaba el valor de su firma al duque de Lerma, con la diferencia de que Licurgo vería por el bien del reino. ${ }^{2}$

El monarca pide al legislador: "Derogad costumbres, usos, / ordenanzas y decretos; / juzgad causas, haced leyes, / dad castigos y dad premios..." (vv. 1219-1222). Solo le solicita cuatro cosas: primera, hablarle con la verdad; segunda, que sus criados y deudos no tengan

\footnotetext{
${ }^{1}$ Los tratados reformistas se multiplicaron entre 1598 y 1605, arreciaron en 1614 y llegaron a su punto máximo entre 1617 y 1620 (Elliott: 112).

${ }^{2}$ Aunque no es mi intención analizar a los personajes, es preciso señalar que desde la perspectiva de Manuel Delgado, Licurgo también es arrastrado por la pasión, lo cual es cierto en cuanto al amor por Diana; el personaje reconoce sus limitaciones racionales al estar enamorado, por lo que no emite ninguna ley. Sin embargo, no comparto la idea de que la restitución del honor del espartano es una "obsesión enfermiza" (Delgado: 114) y que desciende a la "mediocridad moral" (115). Estas ideas merecen mayor detenimiento. Solo apunto que honor y venganza son partes de un código social que responde a la ideología del período áureo. Deborah Dougherty afirma: "the need to restore honor through vengeance is seen not only as an individual desire, but also as a social obligation" (56). Basta recordar la explicación que da a Telamon antes de batirse y matar a su ofensor: "Esto es ser / honrado, no vengativo" (vv. 2339-2340). De acuerdo con Serafín González, Licurgo vence la adversidad y la pasión (González: 79).
} 
exenciones ni privilegios; tercera, que sea piadoso con las mujeres que tengan flaquezas, $\mathrm{y}$

\author{
Lo cuarto, que a los ministros \\ de justicia tan severo \\ castiguéis, que den al mundo \\ universal escarmiento; \\ porque de todos estados \\ públicos suplicios veo, \\ y déste jamás lo he visto, \\ y persuadirme no puedo \\ que dello la causa sea \\ ser todos justos y rectos; \\ mas que, o ya en los superiores \\ engendra el tratar con ellos \\ amistad, y disimulan \\ con la afición sus excesos, \\ o ellos también son injustos, \\ y con recíprocos miedos, \\ porque callen sus delitos, \\ no castigan los ajenos.
}

(vv. 1309-1326)

En particular esta referencia al compadrazgo y la ilegalidad en el ejercicio de la justicia remiten al período de Lerma. La urgente necesidad de modificar la legislación es planteada por Sancho de Moncada al aconsejar a Felipe III, en 1619, "quitar o mudar las leyes que el tiempo y nuevas circunstancias han hecho inútiles, o dañosas a España" (Moncada: 202-203). Respecto al cohecho a los jueces aludido por el Rey de Creta, el economista señala que hay excesivas leyes, de las cuales muchas no se usan, "y dejan las puertas abiertas a jueces para que aprieten a quién $[s i c]$ quisieren, diciendo que no están abrogadas, y disimulen con quién quisieren, diciendo que no están en uso..." (202). Además, advierte que la ambigüedad de algunas ocasiona denuncias y pleitos. Su conclusión es que todo el daño de España "nace de no haberse guardado las leyes de los esclarecidos progenitores de V. Majestad" (204). Así pues, Ruiz de Alarcón se incorpora, a través del teatro, a la corriente de proponer reformas ante la situación decadente de la Península. 
En la dinámica de la tragedia, antes de plantear leyes, Licurgo se enamora perdidamente de Diana y esto lo desvía de su función pública. El personaje reconoce: "¿Qué bien a Creta dará / leyes justas quien sujeto / vive a tan fuertes pasiones!” (vv. 1398-1400). En cuanto al Rey de Creta, enamorado de la misma dama —ignorándolo Licurgo-, ha intentado deshonrarla a pesar de ser hija de su privado Severo, luego, dado que tiene capitulada su boda con una ateniense por razón de Estado, acepta que el legislador la despose, mas sin renunciar a su pasión. ${ }^{3}$

Hasta el tercer acto, cuando Licurgo se casa y vuelve a la racionalidad, presenta al Rey una serie de leyes, quien, sin conocerlas, le pregunta si desea hacerlas públicas, pero, desde otra óptica, Licurgo responde:
Consultar las voluntades del pueblo en las novedades es el modo de acertallas; porque el vulgo interesado, que tiene el caso presente, descubre el inconveniente que el superior no ha alcanzado; y el que emprende novedad de importancia, antes de hacer esta experiencia, a perder se arriesga la autoridad; que revocar brevemente lo que ha mandado, es mostrar que es liviano en revocar, o fue en mandar imprudente.

Son, pues, el Rey y el Reino quienes deben acordar las leyes, para evitar caer en la afrenta de tener que derogarlas. Al respecto es interesante apuntar que "el régimen de Lerma [...] había intentado introducir los millones en Vizcaya, pero fue obligado a echar vergonzosamente marcha atrás" (Elliott: 140). Por el contrario, Licurgo considera nece-

\footnotetext{
${ }^{3}$ El análisis de Manuel Delgado de la conducta inmoral del Rey de Creta es muy atinado (109-112).
} 
saria la participación social y divulga las leyes antes de que el monarca disponga acatarlas.

La primera ley se refiere al trabajo: los plebeyos, al cumplir 18 años, debían tener un oficio, pues de lo contrario serían condenados a obras públicas. Desde la perspectiva del Rey la ley es rigurosa y difícil de promulgar. Sin embargo, el legislador argumenta, con la idea implícita en la popular sentencia, que la ociosidad es madre de los vicios, y añade: "Principio es de la pobreza / del reino, y lo que destruye / los miembros, le disminuye / el poder a la cabeza" (vv. 2037-2040). Hacía tiempo que muchos pensadores reformistas alzaban la voz contra el ocio. En 1600, Gaspar Gutiérrez de los Ríos, dentro de la línea política tacitista, relaciona la razón de Estado con el trabajo: “QQué es esto que no veamos que la verdadera y fundada razón de estado, después de la religión y conocimiento de Dios, se encierra y consiste en un punto solo: que es atajar todos los caminos a la ociosidad?" (Gutiérrez de los Ríos: 273, 281). Hacia 1613, opina Juan de Aranda: "no ay landre más pestífera, y contagiosa para vna Republica, que la ociosidad" (Aranda: f. 147). El jesuita Pedro de Guzmán, Consultor y Calificador del Santo Oficio, hace una alabanza del trabajo y define su parte contraria: "Es la ociosidad madre de necessidad y principio de toda miseria" (Guzmán: 96); Pedro de Valencia, cronista de Felipe III, escribe un Discurso contra la ociosidad en 1618 (Viñas y Mey: 31-45); y Sancho de Moncada la hace característica de sus compatriotas: "La ociosidad y holgazanería, es vicio de Españoles...” (Moncada: 108).

Las ocupaciones provechosas no se limitan al estamento de los plebeyos, el personaje también asigna ocupación a los nobles. En la segunda ley propone que deben asistir a la milicia durante tres ańos, y si a los 24 no lo han hecho, solo podrán gozar de exenciones — respecto al fisco y la justicia - hasta servirlos. El comentario de Licurgo a la ley es bastante elocuente: "Allí se aumenta el valor, / se aprende el trabajo, y hecho / a peligros, pierde el pecho / a la fortuna el temor" (vv. 2049-2052). Como vemos, la milicia se considera una obligación del estamento dominante que, además, moldea el temperamento mediante la disciplina. La idea detrás de la ley planteada es comprometer seriamente a la nobleza con el monarca. Es bien sabido que tiempo atrás la nobleza había rechazado ir a la guerra, convirtiéndose en cortesana y burocrática. En

\footnotetext{
${ }^{4}$ Fechado en 1608 por el autor; el manuscrito es de 1618
} 
1589, Juan de Mora escribe que "le pareceria mejor vna pica en el hombro, o gouernar una vandera: pero al fin los caualleros de aora no quieren ni buscan esso, porque con la delicada y mal compuesta costumbre de su criança, no quieren el peso y rigor de la guerra" (Mora: 127v). Gaspar Gutiérrez de los Ríos señala: "Y no vayan a la guerra, solos los pobres como hasta aqui se ha hecho, mayor obligacion tienen los ricos de yr a ella" (Gutiérrez de los Ríos: 319). En Del Rey y de la Institución Real, Juan de Mariana especifica que no se dé la cruz de ninguna orden militar a quien no haya servido en la milicia y si ya la tiene que lo haga (Mariana: 543). Llama la atención la coincidencia entre Alarcón y doña Luisa de Padilla Manrique, condesa de Aranda, quien aconseja que la nobleza debe servir tres años en el ejército (Padilla: 46).

En la línea de las peticiones del Rey, por segunda ocasión vemos en la obra un interés por las mujeres, pues la tercera ley estipula que el hombre rico, casado y sin hijos, al morir deje un sustento a su viuda. La situación económica de las viudas pobres era un problema social. En Los treinta y cinco diálogos familiares de la agricultura cristiana publicado en Salamanca, en 1589, el franciscano Juan de Pineda expresa de la mujer cuyo marido ha muerto, que "vive tan desamparada y dejada de todo bien, que ni tiene hacienda, ni parientes que la remedien, ni ella se puede remediar" (Vigil: 197). Hacia 1603, el jesuita Gaspar de Astete, en su Tratado del gobierno de la familia y estado de las viudas y doncellas, aconseja a los fieles caritativos que ayuden a algunas viudas "de las que han menester limosna" (198). Pedro de Valencia, en su Respuesta a algunas réplicas..., señala que los oficiales pobres, las viudas y huérfanos no pueden comprar el trigo por adelantado, sino diariamente a la panadera "que va con cien reventas y ganancias", por lo que se veían en la necesidad de empeñar sus alhajas, casas y camas (Viñas y Mey: 161). Sancho de Moncada advierte que las viudas y los huérfanos mueren.

A diferencia de Sancho de Moncada y Gerónimo de Zevallos, regidor de Toledo (ff. 150-153), que se oponen a la naturalización de los extranjeros, Alarcón propone que quienes quieran vivir en España gocen de las preeminencias de los naturales, pues "la copia de la gente / hace poderoso al rey" (vv. 2071-2072). Su pensamiento, aparte de su origen novohispano, se inserta en la idea de la época de que la clave de la riqueza radica en una población numerosa. El declive demográfico era un problema nacional que venía arrastrándose tiempo atrás, y son abundantes los escritos reformistas que lo abordan. Desde principios 
del siglo xviI, González de Cellorigo había escrito sobre la baja demografía en su famoso Memorial dirigido a Felipe III: "La Diminucion y falta de gente, ha muchos ańos que se siente en estos reynos, la qual no procede tanto de las guerras, quanto de la necessidad y falta de todas las cosas, causada por la flojedad de los nuestros, que es la que los ha desterrado de su patria..." (González de Cellorigo: f. 4). El 6 de junio de 1618 Felipe III sometió a consulta al Consejo Supremo de Castilla sobre la falta de gente y hacienda. Respondiendo a tal solicitud, Fernández de Navarrete señala que las repúblicas tienen "por la mejor renta de su patrimonio y la grandeza y autoridad de su imperio la mucha gente de sus estados; en la cual más consiste el reino que en el mismo rey" (Fernández de Navarrete: 449-546). En las Actas de las Cortes de Castilla de 1623, se asienta:

Los principales fundamentos en que consiste el ser y conservación de una monarquía, son el Patrimonio Real y el Reino, en cuanto se constituye de gente y sustancia con cualquiera dellos que se enflaquezca corre riesgo... Ambas estas dos cosas están en tan miserable estado que se puede decir que ni hay rey ni Reino... (Actas 1916: 34).

El dramaturgo no solo llama la atención sobre el descenso demográfico, sino que propone como remedio una situación igualitaria para los extranjeros. Bien sabemos por economistas, memorialistas y Procuradores de las Cortes de la terrible xenofobia que habían despertado los extranjeros no solo por la firma de asientos sino por la importación de productos manufacturados. El mercader toledano Damián de Olivares, por ejemplo, consideraba que los negociantes extranjeros eran tan perniciosos para la economía que habían hundido al país (c. 1622). En esta línea, para el Rey de Creta la ley puede ser nociva y peligrosa. ${ }^{5}$ No obstante, Licurgo sostiene que la gente extraña se hace propia por la amistad, el trato y la vecindad: "porque a darle el tiempo viene / hijos y caudal en ella; / y no hay más patria que aquella / donde tales prendas tiene" (vv. 2081-2084). Algunas voces se alzaban en el sentido de repoblar España con extranjeros (Mariana: 551). ${ }^{6}$ El 14 de octubre de

\footnotetext{
${ }^{5}$ El Rey argumenta que el tener una población española numerosa es bueno, “...que de la extraña, / antes sospecho que daña / y es peligrosa la copia” (vv. 2074-2076).

${ }^{6}$ Aunque el padre jesuita se refiere a la producción, consideraba conveniente llamar oficiales extranjeros (551).
} 
1617 se señaló en las Cortes que se permitiera la entrada de hilo para que oficiales y mercaderes extranjeros poblaran España, "y se henchirá de gente, que es la mayor necesidad que hoy tiene..." (Actas 1909: 461). Años después, el conde-duque de Olivares formaría una Junta de Población para fomentar la industria y atraer extranjeros.

La quinta ley trata sobre el salario de los oficios de justicia y reglamenta que no se pague a los ricos, sino solo a los pobres, "que el rico no ha menester / más premio que el cargo honroso" (vv. 2087-2088). Ante la posible negativa del monarca a la ley, Licurgo añade: "Ni por esto es de temer / que quien sirva ha de faltar; / que es poderoso el mandar, / y es hechicero el poder" (vv. 2093-2096). En respuesta a la Consulta que hizo Felipe III al Consejo de Castilla el $1^{\circ}$ de febrero de 1619, uno de los puntos que proponía para evitar egresos era que el monarca tuviera en consideración los gastos del tesoro público a la hora de conceder mercedes (Elliott: 118). Asimismo, Pedro Fernández de Navarrete señaló a Felipe III, aparte de que la despoblación se debía a los tributos y a no traer extranjeros para repoblar España, que era necesario que los reyes se moderaran en las dádivas (Fernández: 452). Es muy factible que Alarcón, como en otras obras, ${ }^{7}$ siguiera la idea de Juan de Mariana, quien aconseja al rey: "confíe á los poderosos el ejercicio de las magistraturas y cargos públicos, para que léjos de cobrar sueldo del Estado, los consideren como honoríficos y consuman en su desempeño parte de su riqueza..." (Mariana: 563-564). Si nos ubicamos en 1621, las observaciones de Licurgo parecen una réplica a la dificultad de la tentativa de reducir los favores del rey después de las primeras Cortes del reinado de Felipe IV. Don Francisco de Contreras argüía: "Todas las personas que sirven a $\mathrm{V}$. Majd. en paz y en guerra aspiran generalmente a las mercedes y premios... y si supiesen que V. Majd. se prohíbe a sí mismo por ley el no podérselas hacer, o dejarían de servir o servirían con desconfianza" (Elliott: 131).

Era tal el recelo que había sobre el enriquecimiento de los ministros que en enero de 1622 se intentó investigar los orígenes de su riqueza. El mismo mes se publicó un decreto que estipulaba que todos los que habían tenido cargos a partir de 1592 debían inventariar sus propiedades ante un juez (124). Como sabemos, el chivo expiatorio de don Baltasar de Zúniga y Olivares fue don Rodrigo Calderón.

${ }^{7}$ Los pechos privilegiados y La crueldad por el honor. 
Por último, el legislador propone que los delincuentes — maldicientes, embusteros o ladrones - no sean desterrados, pues seguirían con sus costumbres donde fueran desconocidos. La exposición a la vergüenza pública de quienes infringían las normas de convivencia social suponía una vida armónica al desenmascarar el ocultamiento tras las apariencias.

Una ley que no aparece comentada por Licurgo, sino por el gracioso, es la restricción en la venta de vino. Sobre este punto Mariana sustenta que debe limitarse la plantación de viñas, porque "todos, sin distinción de edad ni sexo, se entregan al vino ni mas ni menos que á los demás placeres" (Mariana: 551). Sancho de Moncada coincide en que hay que reducirlas, principalmente "porque la demasía que hoy hay de ello es causa de muchos vicios, y efemina el reino" (Moncada: 194).

Por otro lado, en La crueldad por el honor, el gracioso Zaratán -inclinado al legislador ateniense Solón- plantea a Nuño, rey impostor, una serie de arbitrios, ya "que en Zaragoza se ha dicho / que pretendes reformar / leyes, costumbres y fueros..." (vv. 2033-2035). Hay algunas propuestas que llaman la atención, en particular sobre los pleitos, los precios, el trabajo masculino y los tributos. En cuanto a los pleitos considera que como son peste de la quietud y las haciendas, el letrado sea quien pague los gastos del condenado. De esto resultaría que no hubiera quien defendiera las causas injustas. Esta reglamentación, desde su perspectiva, disminuiría la enorme cantidad de litigios. La aplicación de las leyes y la función de los letrados era un viejo problema. La hipérbole del padre Mariana nos permite hacernos una idea de la situación problemática que había en torno a los litigios, pues sugiere que debe "imaginarse algún medio para que no puedan alargarse los pleitos hasta lo infinito" (Mariana: 534). González de Cellorigo señala que muchos hombres de letras "con celo de justicia alteran, y revuelven la republica y consumen con pleitos [...y] tienen llenos los tribunales superiores de sentencias agraviadas..." (González de Cellorigo: f. 56). El 10 de abril de 1612, los Procuradores de las Cortes se proponen estudiar si es necesario pedir a Felipe III que "mande reformar y dar orden conveniente para que los abogados no lleven la excesiva cantidad de mrs. que acostumbran a los pleiteantes por los inconvenientes que de ello resultan" (Actas 1907: 299). Pedro de Valencia, en su texto Sobre el acrecentamiento de la labor de la tierra, señala que antiguamente se atendía más a las leyes y a mejorar el estado público que a los pleitos (Viñas y Mey: 54). 
Zaratán también se refiere al alza de los precios de la fruta, pues en la cosecha se vende cara y después barata; su propuesta es que se inviertan los $\operatorname{costos}^{8}$ Pero, además, los labradores generalmente se veían obligados a vender sus productos agrícolas por adelantado, y mercaderes y revendedores aumentaban los importes. Las quejas contra la carestía son múltiples, un lugar común, y las explicaciones van desde la firma de asientos, la acuñación de moneda de vellón, la mala conciencia de los mercaderes - recordemos la idea de Quevedo expresada en El buscón, de que "conciencia en mercader es como virgo en cantonera, que se vende sin haberle"-, los censos y juros, hasta los fundamentos económicos de la escuela de Salamanca (circulación excesiva de numerario, proteccionismo deficiente, falta de industrialización, la ley de la oferta y la demanda), ${ }^{9}$ entre otros motivos. Los remedios que se proponen corresponden a las causas.

Otro de los arbitrios que sugiere el personaje del donaire es que, dado que hay escasez de mano de obra para los oficios y la labranza, lo cual encarece los salarios, no se admitan los hijos de quienes se ocupan en dichos menesteres en el estudio de las letras, ni por estas se les den plazas de jueces, pues volverían a sus costumbres. Aunque la ley parece radical, no hay que olvidar que los seminarios y universidades creados por orden del Concilio tridentino eran de muy bajo nivel: no hacían exámenes, se acreditaba por la asistencia, había muchos días festivos, etcétera. La Facultad de Artes, por ejemplo, era una prolongación de las escuelas de gramática, cuyas enseñanzas eran deficientes (Domínguez Ortiz: 321-322). En 1608, Pedro de Valencia plantea que debe haber orden en los estudios de gramática por su baja calidad, y censura que los hijos de labradores y oficiales estudien (Viñas y Mey: 37). Fernández de Navarrete coincide con la idea, pues el estudio implicaba que abandonaran el arado y los instrumentos mecánicos (Fernández: 541). Tales actividades estaban en el olvido, debido a la falta de industrialización, el retraso tecnológico de los gremios y la ideología aristocrático-señorial que sustentaba buena parte del honor en el otium cum dignitate.

\footnotetext{
${ }^{8}$ En el Guzmán se da noticia de este negocio; dice el pícaro: "Antojábaseme que la honra era como la fruta nueva por madurar, que dando por ella excesivos precios, todos igualmente la compran..." (Alemán: 263).

${ }^{9}$ Luis Ortiz, Martín de Azpilcueta, Tomas de Mercado.
} 
En la época, el juego de cartas, entre otros juegos de azar, era uno de los pasatiempos masculinos comunes. De ahí que se proponga un arbitrio que, aunque podría parecer banal, era parte de la vida cotidiana: que no se prenda a los jugadores de naipes. Su importancia radica en que el personaje revela la incongruencia de algunas leyes vigentes en el siglo XVII, ya que se permitía la venta de naipes y en el dos de espadas decía: "con licencia del rey".

Zaratán también plantea que no se impongan tributos en las cosas precisas para vivir, sino en las voluntarias, como los coches, las guarniciones de vestidos, los juegos, las fiestas, bailes y paseos. De tal modo el impuesto se pagaría por gusto y no sería arbitrario. Esto incorporaría a pagar gravámenes a quienes pertenecían al estamento dominante, que se negaba a pechar. Al respecto, Juan de Mariana considera que solo deben imponerse módicos tributos en los artículos de primera necesidad, y ańade: "grávese, por lo contrario, con lo que en esto se disminuya los artículos de puro recreo y lujo..." (Mariana: 549). Ya en el reinado de Felipe IV, Gil González D’Ávila, su cronista, escribe que el rey considera que la despoblación se debe a las pesadas contribuciones que, como sabemos, tenían asolada a la población de escasos recursos (González D’Ávila: 340$){ }^{10}$

Otra norma es que los varones no se ocupen, sentados, en cosas que pueden hacer las mujeres, como las ventas de hilo y seda. En el mismo tenor, Pedro de Valencia opina que los hombres deben realizar oficios pesados y fuera de su casa, "pero que no sean tejedores ni oficiales de sastres, ni sederos, ni hilen [...], ni anden por las calles con un cesto de fruta [...pues] andan muchos hombres muy grandes ocupados en esto" (Viñas y Mey: 43). ${ }^{11}$ Dado que el rey le ofrece mil ducados por los

${ }^{10}$ Sancho de Moncada no está de acuerdo en cargar la alcabala a las cosas superfluas, ya que como no son necesarias, no se comprarían. Sugiere poner tasa fija al trigo y la cebada que todos consumen (Moncada: 177-188 y ss.).

${ }^{11}$ Otras leyes que propone el gracioso son: que el rey venda las plazas y oficios, pues habrá muchos que las compren; que no destierren las mujeres de hombres casados, pues se irán tras ellas y tendrán con sus cuernos penitencia; que cuando haya toros y fiestas se arrienden los terrados de abajo, pues los de arriba tienen altos precios; que los que premia el rey con oficios no aleguen que es por servicios; que dado que no se remedia el problema de los garitos, que se venda el oficio de garitero; que las mujeres no anden rebozadas, sino que se tapen las rameras, y así las damas andarán descubiertas. 
arbitrios, el gracioso expresa: "El primero he sido / que por ser arbitrista he enriquecido" (vv. 2113-2114).

Recapitulando, un principio fundamental es que en la formulación de leyes no solo debe haber congruencia, sino incorporar la participación popular. En cuanto a las propuestas legales, desde la perspectiva económica, se observa la necesidad de que el pueblo trabaje, de evitar egresos en el alza del salario y en retribuir a los ricos, que los hombres hagan labores propias de su sexo, que se regulen los precios y los tributos, y que se repueble con extranjeros; en cuanto a la milicia, que los nobles refuercen el ejército y al mismo tiempo, se formen y templen en la disciplina; respecto a las costumbres, amparar a las viudas, desenmascarar a los transgresores sociales, evitar la embriaguez y rechazar los abusos de los letrados.

Ahora bien, el programa de reforma de Mateo Lisón y Biedma, procurador de Granada, propuesto después de la reunión de las primeras Cortes de Felipe IV en junio de 1621, coincide en algunos puntos que se encuentran en las obras alarconianas: insistía en la unidad del rey y el reino, la despoblación, los abusos en la recaudación de impuestos, en proclamar leyes sobre el lujo, la necesidad de una reforma judicial y administrativa, y la reducción del número de oficiales (escribanos y recaudadores de impuestos). Al no ser considerada una tarea de las Cortes, la reforma de Lisón fracasó. Al final del primer año del reinado de Felipe IV no había logros y, dado que la Junta de Reformación resultó un desastre, surgió la Junta Grande de Reformación en agosto de $1622 .{ }^{12} \mathrm{El} 20$ de octubre el rey firmó una carta donde se recogían, entre otras recomendaciones, reducir en dos tercios el número de escribanos, recolectores de impuestos y alguaciles, evitar gastos superfluos e innecesarios y tomar medidas sobre el lujo. Una de las cuestiones centrales era la disminución de la población; la propuesta para combatirla consistía en animar a artesanos extranjeros católicos para que vivieran en España (Elliott: 133-134).

Las coincidencias de las leyes sugeridas por Ruiz de Alarcón con los pensadores reformistas o con las propuestas de Lisón y Biedma u Olivares, nos permiten observar el conocimiento y la precepción del dramaturgo novohispano sobre la situación de la Península, hayan sido

\footnotetext{
${ }^{12} \mathrm{Su}$ constitución se comunicó a las 18 ciudades representadas en las Cortes de Castilla mediante una carta del rey con fecha de 3 de septiembre de 1622.
} 
escritas las obras estudiadas antes o después de 1621 o 1622. Desde la perspectiva de Lola Josa, el estudio de la obra de Alarcón revela "tintes de consciente compromiso político con Olivares", más aún por compartir el pensamiento del padre Mariana, protegido del conde-duque (107). Las relaciones saltan a la vista. Podríamos concluir que, si bien Alarcón se ha distinguido como moralista, también tenía algunas ideas económicas y legislativas muy claras.

El dramaturgo presenta en ambas obras los problemas que estaban vigentes en el siglo XVII. Propone soluciones reformistas en el ámbito económico, político y social, como en muchas de sus obras. No obstante, si el cambio, en el más estricto sentido senequista, no parte del propio individuo, no hay posibilidad de reforma social. Ante el público y el lector del período áureo se abría la posibilidad de considerar imposible llevar a cabo estas modificaciones por el sentido moral de las tragedias. ${ }^{13}$ En El dueño de las estrellas el personaje que ostenta el poder es un rey movido por las pasiones, sin escrúpulos, que usurpa el lecho del legislador, quien para no matarlo, venciéndose a sí mismo y a los astros, se suicida. En La crueldad por el honor, el rey impostor, que ha premiado los arbitrios del gracioso, no logra enfrentarse a la degradación moral de los cortesanos -empezando con el privado Bermudo que gozó a su esposa-y perece a manos de quien suponía su hijo. Los personajes que podían modificar la monarquía, un privado legislador y un rey impostor, fenecen por la devaluación del ethos aristocrático. En ambos casos no tiene solución de continuidad la reforma propuesta, pues para Alarcón la transformación social era una cuestión ética que partía del individuo, cuyo ejemplo se irradiaría en la sociedad. El ocio, la mezquindad, la hipocresía, el despilfarro, el abuso de poder, la corrupción entrañaban una conducta inmoral que debía erradicarse de acuerdo con el dramaturgo novohispano. Los medios para hacerlo se encuentran planteados a lo largo de la dramaturgia alarconiana con un indudable referente ético estoico: el dominio de sí mismo mediante el uso de la razón. De tal forma, el remedio, detrás de cualquier ley, estaba primero en la cabeza del Estado y sus colaboradores, quienes para

\footnotetext{
${ }^{13}$ Para Edward Friedman, El dueño de las estrellas "is the only one of Alarcon's twenty three plays which conforms with Lope's requisites for tragedia” (430). En cambio, La crueldad por el honor la considera una tragicomedia (436). Desde mi perspectiva, sin embargo, esta última es una tragedia social (Campbell 2010).
} 
ser capaces de aplicar la justicia debían primero vencer sus pasiones racionalmente y llegar a ser virtuosos. ${ }^{14}$ En su Tratado contra los juegos públicos, esta es la idea de Juan de Mariana (461) y la de Séneca a lo largo de su obra: cambiar las costumbres y mantener a los ciudadanos en la virtud, para procurar el bien común.

La definición de tragedia del profesor Francisco Ruiz Ramón implica que el hado se cumple a través de la decisión del héroe trágico. La obra inicia con el oráculo febeo que dice al Rey de Creta: "Pide a Licurgo el árbol venturoso" (v. 17). La interpretación es que debe gobernar acompañado de Licurgo para asegurar la paz del reino. El Rey pretende ser justo, no obstante, hay un anuncio de los astros: el héroe matará o será muerto por un Rey. La seguridad del monarca sobre el poderío de la razón sobre el influjo de las estrellas y la certeza en el consejo de Apolo, llevan a Licurgo a aceptar legislar Creta.

En la tragedia se tratan varios temas: lo sobrenatural, en el oráculo, las estrellas y los agüeros; el político, en la legislación para la paz; el amoroso, del Rey y Licurgo por Diana, y de Marcela por Licurgo; el honor y la justicia. Sobre el texto se ha dicho que la catástrofe es desatinada y hay muchos incidentes (Lista), que es una obra fría y sin inspiración (Castro Leal), en la cual los personajes pierden sus perfiles.

El tema que va a desencadenar la tragedia es el amor. Diana y el monarca mantienen un amor que presenta el obstáculo de la futura boda del Rey con una princesa ateniense, con el fin de garantizar armonía entre los reinos. Situación similar a Los pechos privilegiados. Licurgo, enamorado de la dama, llega a casarse con ella, pero sin culminar el matrimonio. La razón de esta situación es que no ha aceptado la medalla honorífica del Rey por haber sido deshonrado por Teón, hermano de Diana. El hecho de haber recibido una bofetada es considerado inútil en la trama. No obstante, juega una función respecto a la aplicación de la ley.

El ascenso de Felipe IV al lado de don Baltasar de Zúńiga y su sobrino, el conde-duque de Olivares, quien pronto sería su privado, se enfrentó a una cruda realidad económica; se dice en el Consejo de Hacienda:

${ }^{14} \mathrm{Tal}$ es el caso de Los favores del mundo, Los pechos privilegiados o La amistad castigada. 
No se sabe cómo se podrá acudir, no solo a lo que será menester el año que viene, pero ni al cumplimiento de lo que falta de este de $1621 \ldots$ El dinero con que han proveido los gastos que se han hecho este ańo no ha sido de las rentas de él, sino de años adelante hasta el de 1625 (Domíngez Ortiz).

\section{BibLIOGRAFÍA}

Actas de las Cortes de Castilla. Madrid: Imprenta Nacional, 1907, ts. 27-28; 1909, t. 30; 1916, t. 39.

Alemán, Mateo. Guzmán de Alfarache. Ed. Francisco Rico. Barcelona: Planeta, 1983.

ARANDA, JuAN DE. Lvgares comvnes de conceptos, dichos y sentencias con diuersas materias. Madrid: 1613 (BNM, R 4481).

CAmpbell, Ysla. “'Es la comedia un espejo': el ethos nobiliario en La crueldad por el honor, de Juan Ruiz de Alarcón”, en Cuatrocientos años del Arte nuevo de hacer comedias, de Lope de Vega. Actas selectas del XIV Congreso de la Asociación Internacional de Teatro Españoly Novohispano de los Siglos de Oro (Olmedo 2009). Eds. Germán Vega García-Luengos, Héctor Urzáiz Tortejada. Valladolid, Universidad de Valladolid / Ayuntamiento de Olmedo, 2010: 305-311.

Delgado Morales, Manuel. "Significado político de la moral y de la justicia en El dueño de las estrellas", en Josep María Solá-Solé: homenaje. Miscelánea de estudios de amigos y discípulos. Estudios misceláneos I. Ed. Torres Alcalá. Barcelona: Puvill Libros, 1984: 109-117.

Dougherty, Deborah. “Alarcón's Licurgo: A Magnanimous Hero's Honorable Vengeance", en Bulletin of the Comediantes, 47, 1 (1995): 55-71.

Domínguez Ortiz, Antonio. El antiguo Régimen: Los Reyes Católicos y los Austrias. Madrid: Alianza, $7^{\mathrm{a}}$ ed., 1980.

Elliott, J. H. El Conde-Duque de Olivares. Barcelona: Crítica, 6a ed., 1991.

Fernández de Navarrete, Pedro. Conservación de monarquías. Madrid: Rivadeneyra, 1926: 449-546 (BAE, t. 25).

Friedman, EDWARD H. "A view of Tragedy and Tragicomedy in Ruiz de Alarcon's El dueño de las estrellas y La crueldad por el honor", en Kentucky Romance Quarterly, 22 (1975): 429-441.

GonzÁlez, Serafín. "La trayectoria de Licurgo en El dueño de las estrellas", en Alarconiana. Ed. Ysla Campbell. Ciudad Juárez: Universidad Autónoma de Ciudad Juárez, 2011: 79-91.

GonzÁlez D’ÁvilA, Gil. Teatro de las grandezas de la Villa de Madrid. Madrid: 1623 (BNM, U 7688). 
González de Cellorigo, Martín. Memorial de la Política necessaria, y útil restauración a la Republica de España, y estados della, y del desempeño universal de estos Reynos. Valladolid: 1600 (BNM, VE 207-6).

Gutiérrez de los Ríos, Gaspar. Noticia general para la estimación de las artes. Madrid: 1600 (BNM, R 28056).

Guzmán, Pedro De. Los bienes del honesto trabajo y daños de la ociosidad en ocho discursos. Madrid: 1614 (BNM, 7707).

JosA, LolA. "De tiranos y de hombres en el teatro de Juan Ruiz de Alarcón", en El teatro clásico español a través de sus monarcas. Ed. Luciano García Lorenzo. Madrid: Fundamentos, 2006: 105-117.

Mariana, Juan De. Del Rey y de la Institución Real, Tratado contra los juegos públicos, en Obras del padre Mariana. Madrid: Rivadeneyra, 1854 (BAE, t. 31).

Moncada, Sancho De. Restauración política de España. Ed. Jean Vilar. Madrid: Instituto de Estudios Fiscales, 1974.

Mora, Juan DE. Discursos morales. Madrid: 1589 (BNM, R 13816).

Olivares, Damián DE. A la Imperial civdad de Toledo. Madrid: c. 1622 (BNM, VE 210-99).

Padilla Manrique, Luisa de. Nobleza virtuosa. Zaragoza: 1637 (BNM, R 9610).

Ruiz de Alarcón, Juan. Obras Completas de Juan Ruiz de Alarcón. Ed. Agustín Millares Carlo. México: Fondo de Cultura Económica, $2^{a}$ ed., 1979, t. II.

VigIL, MARILÓ. La vida de las mujeres en los siglos XVI y XVII. Madrid: Siglo XXI, 1986.

ViÑas y Mey, Carmelo. Pedro de Valencia. Escritos sociales. Madrid: Escuela Social de Madrid, 1945 (Discurso contra la ociosidad, Sobre el acrecentamiento de la labor de la tierra, Respuesta a algunas réplicas que se han hecho contra el discurso del precio del pan, para el RVMO. Confesor de S. M. el padre fray Diego Mardones).

Zevallos, Gerónimo De. Arte real para el buen gobierno de los Reyes, y Príncipes, y de sus vassallos. Toledo: 1623 (BNM, R 27402). 